\title{
PENERAPAN MODEL PEMBELAJARAN BAHASA ARAB BERBASIS SAVI (Somatis, Auditori, Visual, Intelektual) DALAM MENINGKATKAN HASIL BELAJAR PADA PESERTA DIDIK
}

\author{
Koderi \\ koderiuinlampung@gmail.com \\ Universitas Islam Negeri (UIN) Raden Intan Lampung
}

\begin{abstract}
This research is focused on to cope with the problems commonly encountered by students in learning Arabic including low retention, low motivation, lack of skills and unsatisfactory learning achievement due to insufficient learning facilities and variations. This study is aimed at acquiring obtaining empirical data "The influence of Arabic language-based learning model SAVI (somatic visual auditory intellectual) in improving the learning outcomes of students of class VIII in MTs Negeri 2 Bandar Lampung in 2016/2017". This study is a quasi-experimental research (quasi experimental research). Based on the analysis of homogeneity is known that both data result of learning the Arabic language learners class VIII G (experimental class) and the result of learning the Arabic language learners class VIII $F$ (control group) have the same variance (homogeneous). So as to test the hypothesis can be used t-test. The calculation result obtained using $t$-test, $t$-test $=4.698$ and of the distribution table at significant level known $t_{\text {tabel }}=2.00$ therefore $t_{\text {hit }}>t_{\text {table. }}$. The results of these calculations at the same time also shows that the application of the model of learning Arabic based SAVI can significantly affect the learning outcome Arabic language learners because learning model Arabic-based SAVI can make students more creative, independent, more active and feel unfettered in the learning process in the classroom.
\end{abstract}

Keywords: Arabic, Learning, Models, SAVI

\section{PENDAHULUAN}

Belajar bahasa Arab bagi peserta didik di Madrasah Tsanawiyah (MTs) sebagaimana belajar bahasa asing lainnya yaitu memiliki kendala-kendala dalam proses pembelajaran. Kendala-kendala dalam pembelajaran bahasa yaitu adanya perbedaan bunyi, bentuk kata, struktur kalimat, sistem penulisan, hal ini menjadi masalah yang harus dihadapi oleh peserta didik karena bahasa Arab berbeda dengan bahasa Ibu. Adanya stigma yang berkembang di masyarakat bahwa belajar bahasa Arab masih dianggap sulit dan rumit, padahal setiap bahasa memiliki tingkat kesulitan dan kemudahan yang berbeda-beda tergantung pada karakteristik sistem bahasa itu sendiri, baik sistem fonologi, morfologi, maupun sintaksis dan semantiknya. Faktor lain yang dapat mempengaruhi proses dan hasil belajar bahasa Arab yaitu faktor dari dalam diri peserta didik (internal) seperti minat, bakat, motivasi, sedangkan faktor dari luar (eksternal) seperti guru, kurikulum, silabus, bahan ajar, model 
pembelajaran yaitu strategi, media dan evaluasi.

Berdasarkan hasil wawancara dengan tiga orang guru bahasa Arab di MTs Negeri 2 Bandar Lampung didapatkan keterangan bahwa guru bahasa Arab dalam mengajar banyak mengalami masalah antara lain 1) motivasi peserta didik rendah untuk menggali pengetahuan dan ketrampilan bahasa arab yang dipelajari; 2) peserta didik sulit mengingat (retensi) isi atau materi; 3) peserta didik tidak mampu mengaplikasikan pengetahuan dan ketrampilan bahasa Arab yang telah dipelajari dalam kontek hubungan interaksi di kelas maupun di luar sekolah; 4) sehingga berimplikasi pada prestasi belajar bahasa Arab peserta didik yang rendah.

Menurut Kim dan Frick (2011). "Internal factors are related to the features of the course it self that can influence the learner's motivation. External factors refer to aspects of the learning environment that can influence the learner's motivation". Faktor internal dapat mempengaruhi motivasi peserta didik, motivasi dapat dipengaruhi aspek lingkungan sebagai faktor eksternal.

Selanjutnya, menurut Lee dan Reeve bahwa: "Being aware of, monitoring and responding constructively to students' motivation signals during instruction is an important teaching skill. This is so because classroom motivation and retention is a reliable predictor of students' subsequent engagement, learning and achievement". Bahwa sadar akan pentingnya suatu model pembelajaran yang konstruktif yang mampu memberikan arah dan respon terhadap motivasi selama proses pembelajaran, maka motivasi dan retensi adalah sebagai kunci untuk mencapai keberhasilan prestasi peserta didik.

Oleh karena itu agar proses pembelajaran di MTs Negeri 2 Bandar Lampung berjalan lebih efektif dalam meningkatkan ketrampilan dan hasil belajar bahasa Arab, maka aktivitas gerak tubuh, kecerdasan auditori, visual dan intelektual yang dimiliki oleh peserta didik harus digabungkan dalam satu peristiwa pembelajaran, baik itu pembelajaran bahasa Arab maharah alistima', maharah al-kalam, maharah alkitabah maupun maharah qiro'ah.

Menurut Meier yang dikutib oleh Iskandar (2016:47), "Reveals also that learning is not a separate cognitive event but something that involves the whole person (body, mind and soul) and the intelligence intact.Opinion was delivered Meier in a research conclusion that man has a dimension of somatic, auditory, visual and intellectual. Based on this view 
Meier propose an active learning approach called SAVI approach. SAVI approach is pressed learning by utilizing the senses of students. Explains that the model of SAVI is a learning model that combines four student learning that is somatic, auditory, visual, and intellectual. Where in this learning model learning students can move, speak or hear, see and think directly what they are learning, so that learning becomes more meaningful.

Pembelajaran bukanlah peristiwa kognitif yang terpisah namun sesuatu yang melibatkan keseluruhan pribadi (tubuh, pikiran dan jiwa) dan seluruh kecerdasan. Pembelajaran tersebut menggabungkan empat kecerdasan yaitu somatik, auditori, visual, dan intelektual. Model pembelajaran ini memberikan keluasan pada peserta didik bisa bergerak, berbicara, mendengar, melihat dan berpikir secara langsung apa yang mereka pelajari, sehingga pembelajaran menjadi lebih bermakna. Model pembelajaran bahasa Arab tersebut dinamakan model pembelajaran bahasa Arab berbasis SAVI (Somatis, Auditori, Visual, dan Intelektual).

Ruang lingkup masalah dalam penelitian ini adalah "Pengaruh model pembelajaran bahasa Arab berbasis SAVI (Somatis Auditori Visual Intelektual) dalam meningkatkan hasil belajar peserta didik kelas VIII di MTs Negeri 2 Bandar Lampung tahun 2016/2017."

Penulis merumuskan masalah "Apakah terdapat perbedaan pengaruh yang signifikan antara peserta didik yang diberikan model pembelajaran bahasa Arab berbasis SAVI (Somatis Auditori Visual Intelektual) dengan peserta didik yang diberi pembelajaran konvensional terhadap hasil belajar?

Berdasarkan rumusan masalah diatas, maka tujuan penelitian ini adalah untuk mengetahui apakah terdapat perbedaan pengaruh yang signifikan antara peserta didik yang diberi model pembelajaran bahasa Arab berbasis SAVI (Somatis Auditori Visual Intelektual) dengan peserta didik yang diberi pembelajaran konvensional terhadap hasil bahasa Arab. Penelitian ini diharapkan: 1) dapat memberikan sumbangan pemikiran terhadap guru, tentang menggunakan model pembelajaran bahasa Arab berbasis SAVI (Somatis Auditori Visual Intelektual) sebagai inovasi dalam proses pembelajaran. 2) dapat membantu dan memfasilitasi peserta didik, tentang mengembangkan kecerdasan dalam belajar bahasa Arab melalui model pembelajaran berbasis SAVI (Somatis, Auditori, Visual, Intelektual). 3) dapat 
memberikan masukan kepada kepala sekolah dalam meningkatkan kualitas pembelajaran melalui model pembelajaran bahasa Arab berbasis SAVI (Somatis Auditori Visual Intelektual).

\section{LANDASAN TEORI}

Model adalah representasi dari suatu bentuk proses, produk, dan ide-ide atau pola pikir dari seseorang dalam mewujudkan suatu tujuan, yang dapat digambarkan dalam bentuk grafis dan/atau naratif. Menurut Gustafson dan Branch (2002:1) bahwa model "A simple representation of more complex form, processes, and functions of physical phenomena or ideas. Briggs (1979:113) menegaskan bahwa: "Model- a set of coherent procedures for actually carrying out a process, such as needs assessment, media selection, or evaluation". Model adalah satu set prosedur yang koheren untuk digunakan dalam melaksanakan suatu proses pekerjaan, seperti penilaian kebutuhan, pemilihan media, atau evaluasi.

Pembelajaran menurut Gagne dan Briggs (2005:19), "Instruction is the means employed by teachers, designers of materials, curriculum spicialists, and others whose purpose it is to develop an organized plan to promote learning”.
Pembelajaran adalah suatu kegiatan yang dilakukan oleh guru, ahli perancang materi, dan ahli kurikulum tertentu, dalam rangka untuk mengembangkan rencana kegiatan dengan maksud untuk meningkatkan belajar.

Selanjutnya, model pembelajaran menurut Reigeluth "Instructional model (not to be confused with instructional development model; see following discussion) is usually an integrated sef of strategy componenfs, such as: the pafticular way the content deas are sequenced, the use of overuiews and summaries, the use of examples, the use of practice, and the use of different strategies for motivating the students". Artinya model pembelajaran adalah suatu set komponen yang terintegrasi, meliputi ide-ide, cara-cara tertentu, penggunaan ikhtisar, ringkasan, penggunaan contohcontoh, penerapan praktik atau latihan, dan penggunaan strategi pembelajaran yang dilakukan secara berurutan dalam menyampaikan materi pembelajaran untuk memotivasi para peserta didik dalam mencapai tujuan pembelajaran.

Menurut Joyce (2009:6), "Models of teaching are really models of learning. As we help students acquire information, ideas, skills, values, ways of thinking, and means of expressing themselves, we are 
also teaching them how to learn. In fact, the most important long-term outcome of instruction may be the students increased capabilities to learn more easily and effectively in the future, both because of the knowledge and skill they have acquired and because they have mastered learning processes.". Model pembelajaran adalah upaya membantu peserta didik agar mereka mendapatkan informasi, gagasan, skill, nilai, cara berfikir, tujuan dan mengekspresikan diri. Model pembelajaran hakekatnya adalah bagaimana guru meningkatkan kapabilitas peserta didik untuk dapat belajar lebih mudah dan lebih efektif, baik untuk mendapatkan kapabilitas pengetahuan dan skill dari sebuah pembelajaran yang lebih baik.

Istilah SAVI merupakan singkatan dari somatic, auditori, visual dan intelektual. SAVI lahir dari sebuah axiomatis tentang Accelerated Learning. Accelerated Learning adalah pembelajaran yang memungkinkan peserta didik untuk belajar dengan kecepatan yang mengesankan, dengan upaya normal, dan dibarengi kegembiraan (Deporter, 1992:14). Pembelajaran SAVI dilandasi pendapat Gardner "That effective teacher need to consider the different learning styles of their student recognezing that student vary widely in terms of strengths and weaknesses in each of these areas (Smaldino, 2008:89)". Menurut pendapat Gardner ini bahwa guru yang efektif harus mempertimbangkan gaya belajar yang berbeda dari peserta didiknya, hal ini karena peserta didik memiliki kekuatan dan kelemahan berbeda-beda.

Pembelajaran SAVI singkatan dari somatis, auditori, visual, dan intelektual. Menurut Matthews yang dikutib oleh Amann (2013:27) mengatakan "Defines somatic knowing as an experiential knowing that involves sense, precept, and mind/body action and reaction-a knowing, feeling, and acting that includes more of the broad range of human experience" Bahwa peserta didik dalam belajar untuk mengetahui sesuatu didasarkan dari pengalaman, untuk mendapatkan pengetahuan dari suatu pengalaman harus melibatkan akal, pikiran dan tindakan tubuh. Untuk itu somatik adalah proses mendapatkan pengalaman belajar dengan melibatkan aktivitas gerakkan tubuh. Pembelajaran somatis yaitu belajar bahasa Arab dengan aktivitas fisik, gerak tubuh, berbuat, dan permainan atau $a l$-'ab (Fachrurrozi, 2010:97).

Pembelajaran auditori yaitu belajar bahasa Arab dengan memaksimalkan 
indra pendengaran (DePoorter, 1992:118). Pembelajaran visual yaitu belajar bahasa Arab dengan memaksimalkan indra penglihatan (Gilakjani, 2012:105) dan pembelajaran intelektual yaitu belajar bahasa Arab dengan memecahkan masalah, latihan, praktik mengimplementasikan penge-tahuan dan ketrampilan bahasa Arab yang telah dipelajari (Meier, 2000:42).

Meier menambahkan "It's the means by which the mind turns experience into knowledge, knowledge into understanding, and under-standing (we hope) into wisdom". Pembelajaran bahasa Arab dituntut menggunakan semua indra, kemudian apa yang diperolehnya harus diterapkan pada pemecahan masalah dan berkomunikasi. Pembelajaran SAVI menganut aliran belajar kognitif modern, yang menyatakan belajar yang paling baik adalah melibatkan emosi, seluruh tubuh, semua indera, menghormati kecerdasan jamak dan gaya belajar individu.

Selanjutnya hakikat belajar, menurut Brown belajar adalah berbagai penggalan kegiatan yaitu:

“1) belajar adalah memperoleh (akuisisi) atau mendapatkan, 2) belajar adalah menyimpan (retensi) atau ketrampilan, 3) belajar adalah berlangsung aktif, sadar terhadap fokus, dan melakukan tindakan,
4) belajar adalah secara relatif permanen, 5) belajar adalah mencakup berbagai bentuk praktik, 6) belajar adalah perubahan perilaku (Asrori, 2011:2012)". Hakikat belajar bahasa menurut Wenden adalah proses kognetif melibatkan empat tahapan, yaitu (a) menyeleksi informasi yang masuk melalui panca indra, (b) memahami informasi, (c) menyimpan (retensi) informasi, dan (d) memanggil informasi.

Bedasarkan hasil penelitian Jado (2015:5), untuk mengembangkan model pembelajaran linguistik berdasarkan filsafat kecerdasan jamak, guru harus menerjemahkan materi linguistik ke dalam aktivitas somatis, auditori, visual, intelektual sesuai teori Multiple Intellgence, yaitu "Develop instruction under the MI philosophy, the teacher has to translate the linguistic materials into activities that cope with MI Theory. The best way to approach curriculum and textbook development using the theory of multiple intelligences is by thinking about how we can translate into the languages of other intelligences, namely those proposed by Gardner in his MI theory (Armstrong, 1994).

Selanjutnya, menurut Kunh dan Udell "Teachers must plan and manage the learning setting to ensure that their 
student are both challenged and successful (Smaldino, 2008: 24)”. Artinya bahwa para guru harus merencanakan dan mengatur lingkungan belajar untuk memastikan bahwa peserta didik mereka tertantang dan berhasil. Marzano menyebutkan "Teacher have a significant impact on their student. The instructional strategies selected by the teachers need to be selective in the choices they make. The theory base and research on theaching suggest that teachers serve as a guide to in enhance student learning (Smaldino, 2008:24)”.

Pendapat Marzano di atas menegaskan bahwa para guru memiliki pengaruh yang signifikan terhadap peserta didik dalam mencapai hasil belajar. Strategi pembelajaran (metode dan media) yang dipilih oleh para guru akan mempengaruhi hasil belajar peserta didik. Oleh karena itu para guru bahasa Arab sebagai pemandu, bertanggung jawab memilih model pembelajaran yang digunakan untuk membantu peserta didik belajar agar berjalan dengan efektif serta membantu peserta didik mencapai hasil belajar yang diharapkan.

Menurut Heinich bahwa:"Empat indikator program pembelajaran yang efektif dan efisien yaitu 1) dapat memfasilitasi peserta didik mencapai kemampuan atau kompetensi yang diperlukan; 2) mampu memotivasi peserta didik untuk menggali pengetahuan dan ketrampilan yang dipelajari; 3) mampu membuat peserta didik mengingat (retensi) isi atau materi pelajaran; dan 4) mampu mengaplikasikan pengetahuan yang telah dipelajari dalam kontek yang tepat (Suparman, 2013:4)".

Menurut Fachrurrozi dan Mahyudin ada problem yang selalu dihadapi dalam belajar bahasa, yaitu: "Problem kebahasaan dan non kebahasaan. Problem kebaha-saan adalah persoalan-persoalan yang dihadapi peserta didik yang berkaiatan langsung dengan bahasa yang sedang dipelajari. Beberapa problem kebahasaan yang sering menghambat dalam belajar bahasa antara lain: 1) problem bunyi, 2) problem kosa kata, 3) problem kiadah tata kata, 4) problem tata kalimat, 5) problem tulisan. Adapun problem nonkebahasaan yang mem-pengaruhi proses dalam belajar bahasa adalah meliputi faktor: 1) psikologi seperti dawafi' (motivasi) dan muyul (minat) belajar, 2) furuq fardiyyah (perbedaan individu), 3) sarana prasarana, media dan sumber belajar, 4) rendahnya kompetensi guru, 5) ketersedian waktu, 6) lemahnya mengembangkan lingkungan belajar bahasa (Fachrurozi, 2012:1-9)". 


\section{METODE PENELITIAN}

Penelitian ini adalah penelitian eksperimental semu (Quasi Eksperimental Research). Variabel bebasnya adalah model pembelajaran bahasa Arab berbasis SAVI dan pembelajaran konvensional, variabel terikatnya adalah hasil belajar. Pengambilan sampel penulis menggunakan teknik sampling purposif atau pertimbangan yaitu kelas VIII G sebagai kelas eksperimen sebanyak 33 orang dan peserta didik kelas VIII F sebagai kelas control sebanyak 33 orang, Tempat pelaksanaan di MTs Negeri 2 Bandar Lampung sebanyak 5 kali pertemukan pada semester ganjil tahun 2016/2017. Teknik pengumpulan data menggunakan tes, observasi, dokumentasi dan interview, analisa data menggunakan uji kesamaan dua rata-rata.

\section{HASIL DAN PEMBAHASAN}

Berdasarkan hasil analisis data diperoleh bahwa nilai rata-rata hasil belajar bahasa Arab kelas eksperimen adalah 78,85 dan untuk kelas kontrol adalah 51,85. Analisis homogenitas diketahui bahwa kedua data hasil belajar bahasa Arab peserta didik kelas VIII G (kelas eksperimen) dan hasil belajar bahasa Arab peserta didik kelas VIII F (kelas kontrol) mempunyai varians yang sama (homogen). Sehingga untuk menguji hipotesis dapat digunakan t-test. Hasil perhitungan menggunakan t-test diperoleh t-test $=4,698$ dan dari tabel distribusi pada taraf signifikan diketahui $t_{\text {tabel }}=2,00$ oleh karena $t_{\text {hit }}>t_{\text {tabel. }}$.

Selanjutnya hasil perhitungan secara keseluruhan menunjukkan bahwa kedua perlakuan jelas berbeda (signifikan), oleh karena itu $\mathrm{H}_{0}$ ditolak yang berarti bahwa penerapan model pembelajaran bahasa Arab berbasis SAVI memberikan pengaruh yang berbeda dengan model pembelajara konvensional terhadap hasil belajar peserta didik pada mata pelajaran bahasa Arabdi kelas VIII G di MTs Negeri 2 Bandar Lampung. Hasil perhitungan tersebut sekaligus menunjukkan kesimpulan bahwa penerapan model pembelajaran bahasa Arab berbasis SAVI secara signifikan dapat mempengaruhi peningkatan hasil belajar bahasa Arab peserta didik, karena model pembelajaran bahasa Arab berbasis SAVI dapat membuat peserta didik lebih kreatif, mandiri, lebih aktif dan merasa tidak terkekang dalam proses pembelajaran di dalam kelas.

Hal ini sejalan dengan pendapat Kozma yang dikutib oleh Choi dan Johnson (2015): “That the visual 
component is memorable, he argued that simultaneous processing of auditory and visual information may aid learning. In addition, video might be superior for learning complex skills because it can expose learners to problems, equipment, and events that cannot be easily demonstrated". Bahwa materi visual akan mudah diingat, proses simultan materi visual dan auditori semuanya dapat membantu proses pembelajaran. Pembelajaran menggunakan Video akan memungkinkan proses pembelajaran akan lebih baik terutama dalam pembelajaran keterampilan karena dapat mengekspos terhadap masalah yang komplek dan sesuatu yang tidak mudah dapat ditunjukkan. Koderi dan Rukimin (2015:102) mengatakan "Penggunaan teknologi multimedia sebagai media pembelajaran bahasa Arab merupakan salah satu alternatif untuk membantu mengatasi masalah belajar peserta didik, karena dengan menggunakan teknologi multimedia (audio, video, visual dan gambar), peserta didik akan mampu belajar bahasa Arab secara mandiri, lebih mudah, nyaman, dan belajar sesuai dengan kemampuannya.

Menurut Zhang et al, (2016:15) "Recent advances in multimedia and communication technologies have resulted in powerful learning systems with instructional video components. The emergence of non-linear, interactive digital video technology allows students to interact with instructional video. This may enhance learner engagement, and so improve learning effectiveness". bahwa penggunaan teks, gambar-gambar, audio, video dan latihan-latihan interaktif dengan mengintegrasikan antara kegiatan somatis, auditori, visual dan intelektual memungkinkan peserta didik dapat meningkatkan aktivitas belajar sehingga efektivitas pembelajaran akan lebih baik.

Hasil penelitian ini mengindikasikan bahwa penggunaan teks, gambar-gambar, audio, video dan latihan-latihan interaktif pada tiap-tiap topik pada model e-modul berbasis SAVI merupakan stimulus yang mampu memberikan respon positif pada peserta didik dalam belajar bahasa Arab.

\section{SIMPULAN DAN SARAN}

Kesimpulan hasil analisis menunjukkan bahwa hipotesis yang menyatakan 1) Penerapan model pembelajaran bahasa Arab berbasis SAVI memiliki pengaruh terhadap hasil belajar pada peserta didik kelas VIII semester ganjil di MTs Negeri 2 Bandar Lampung tahun 2016/2017", teruji kebenarannya. Hasil belajar bahasa Arab pada peserta didik akan lebih baik 
dengan penerapan model pembelajaran bahasa Arab berbasis SAVI. 2) Berdasarkan hasil analisis data diperoleh bahwa nilai rata-rata hasil belajar bahasa Arab kelas eksperimen adalah 78,85 dan untuk kelas kontrol adalah 51,85, hal ini menunjukkan bahwa penerapan model pembelajaran bahasa Arab berbasis SAVI memiliki pengaruh terhadap hasil belajar bahasa Arab peserta didik yang tercermin dalam nilai $t_{\text {hitung }}=$ 4,45 dan $t_{\text {tabel }}=2,00$ oleh karena itu $t_{\text {hit }}>$ $t_{\text {tabel. }}$ Dengan demikian terdapat pengaruh antara model pembelajaran bahasa Arab berbasis SAVI terhadap hasil belajar bahasa Arab peserta didik kelas VIII.

Penulis memberikan

saran

1) Penelitian eksperimen ini diharapkan dapat memberikan masukan kepada guru bahasa Arab untuk mencoba menerapkan model pembelajaran bahasa Arab berbasis SAVI, agar peserta didik lebih aktif dan kreatif dalam proses pembelajaran sehingga dapat meningkatkan hasil belajar. 2) Untuk mendapatkan hasil belajar bahasa Arab yang baik pada peserta didik, dibutuhkan model pembelajaran yang mampu mengaktifkan gerakan atau aktivitas tubuh, kecerdasan auditori, visual dan intelektual sehingga peserta didik termotivasi untuk melaksanakan proses pembelajaran.
3) Untuk lebih meningkatkan efektifitas terhadap hasil belajar bahasa Arab, perlu dilakukan penelitian pengembangan produk lebih lanjut, yaitu penelitian pengembangan model e-modul berbasis SAVI. E-modul SAVI adalah bahan ajar elektronik yang disusun berdasarkan desain pembelajaran dengan mengintegrasikan antara kegiatan somatis, auditori, visual dan intelektual, yang penggunaannya melalui komputer dan android.

\section{DAFTAR PUSTAKA}

Tara L. Amann, Fifth International Conference On Transformative Learning Transfor-mative Learning In Action: Building Bridges Across Contexts And Disciplines (New York: Teachers College Columbia University 525 West $120^{\text {th }} \mathrm{St}, 2003$ ), h.27, Law Reviews, https://meridianuniversity.edu/images/tlc/ roceedings/ TLC Proceeding 2003.pdf (diakses 8 Agustus 2015).

Asrori, Imam. (2011). Strategi Belajar Bahasa Arab Teori dan Praktik. Malang: Miskat Indonesia.

Briggs, Leslie J. (1979). Instructional Design: Principles and Aplications. New Jersy: Educational Technology Publication, Inc., Englewood Cliffs.

Choi, Hee Jun and Scott D. Johnson. (2015). "The Effect of Context-Based Video Instruction on Learning and Motivation in Online Courses", The American Journal of Distance Education, Vol.19 No.4, h. 215, Law Reviews, https://pdfs.Semanticscholar. 
org/291a/db034f78a60ed219e13a3d8

144086a1417fc.pdf (diakses 29

Desember 2016).

DePorter, Bobbi. (1992). Quantum Learning: Unleashing the Genius in You. New York: Bantam Doubleday Dell Publishing Group.

Fachrurrozi, Aziz dan Erta Mahyudin. (2010). Pembelajaran Bahasa Asing, Metode Tradisional dan kontemporer. Jakarta: Bania Publishing.

Gagne, Robert $\mathrm{M}$ and Leslie J. Briggs. (1979). Principles of Instructional Design.New York: Holt, Rinehart and Winston.

Gilakjani, Abbas Pourhossein. (2015). "Visual, Auditory, Kinaesthetic Learning Styles and Their Impacts on English Language Teaching”. Journal of Studies in Education, Lahijan, Iran: Islamic Azad University, vol.1, No.2, Law Reviews, http://dx.doi.org/ 10.5296/ jse.v2i1.1007 (diakses 08 Agustus 2016).

Gustafson, Kent L. and Robert Maribe Branch. (2002). Survey of Instructional Development Models, Third Edition. New York: Eric Clearinghouse on lnformation \& Technology Syracouse University.

Iskandar, Dadang et al. (2016). "Implemetation Of Model Savi (Somatic, Audiotory, Visualization, Intellectual) To Increase Critical Thinking Ability In Class IV Of Social Science Learning On Social Issues In The Local Environment". Journal of Education, Teaching and Learning Vol.1, No. 1. Law Review. http://journal.Stkipsingka wang.ac.id /index.php/JETL/article/.../16 (diakses 29 Desember 2017).

Koderi dan Rukimin (2015), Multimedia Interaktif dalam Pembelajaran Bahasa Arab, Prosiding Workshop Nasional Pascasarjana Program Studi Teknologi Pendidikan Universitas
Sebelas Maret, Solo: 28 November 2015.

Jado, Saleh Mohammad Abu. (2015). "The Level Of Multiple Intelligences In Arabic Language Textbooks For Grades From (1 - 4) In Jordan In Light Of Gardner's Theory. Creative Education, 6, 1558-1572, Published Online August 2015 In Scires. http://Www.Scirp.Org/ Journal/Ce , http://Dx.Doi.Org/10.4236/

Ce.2015.614156, (diakses 29 Desember 2016).

Joyce, Bruce., Marsha Weil, and Emily Calhoun.(2009). Models of Teaching Eigth Edition. New York: Pearson.

Kim, Kyong-Jee and Theodore W. Frick.(2011). "Changes In Student Motivation During Online Learning”, Journal Educational Computing Research, Vol. 44, No.1. Law Reviews, http://journals.sagepub.com /doi/abs/ 10.2190/EC.44.1.a (diakses 29 Desember 2016).

Meier, Dave. (2000). The Accelerated Learning Handbook A Creative Guide to Designing and Delivering Faster, More Effective Training Programs. New York; McGraw-Hill San Francisco Washington, D.C.

Reigeluth, Charles M. (2009). Instructional Design Theories and Models an Overview of Their Current Status. New Jersey: Lawrence Erlbaum Associates, Publisher.

Smaldino, E. S., D.L Lowther and J. D. Russell. (2008). Instructional Technology and Media for Learning, Upper Saddle River, New Jersey: Prince Hall.

Suparman, M. Atwi et al. (2013). "Guru Sebagai Arsitek Pembelajaran Sepanjang Waktu: Mungkin?", Prosiding Seminar Universitas Terbuka. Jakarta: 02 Desember 2013

Zhang, Dongsong et al. (2016). "Instructional video in e-learning: Assessing the impact of interactive 
video on learning effectiveness".

Journal Information \&

Management, Vol 43. Law reviews,

https://pdfs. Semanticscholar.org/

4f6e/a57d ddeb

2950feedd39101c7bd586774599a.p

df (diakses 29 Desember 2017). 